\title{
EL CINE CIENTÍFICO EN LA ARGENTINA DE PRINCIPIOS DEL SIGLO 20: ENTRE LA EDUCACIÓN Y EL ESPECTÁCULO
}

DOI: http://dx.doi.org/10.1590/2236-3459/47763

\author{
Andrea Cuarterolo \\ Conicet/Universidad de Buenos Aires, Argentina.
}

Resumen

Los primeros films científicos argentinos fueron mayoritariamente productos por encargo, que se rodaron en las mismas compañías productoras y con algunas de las mismas estrategias formales, temáticas y de mercado del cine comercial. Es así que, lejos de constituir un material accesible sólo para especialistas, estas películas se proyectaron con frecuencia en salas comerciales, se publicitaron en las revistas de la época y en ocasiones se convirtieron en verdaderos éxitos de taquilla. A partir de un recorrido por algunos de los principales films de esta temática, mostraremos que, así como el cine se convirtió en parte integral del mundo médico-científico de la época, la ciencia fue un componente importante de la industria del entretenimiento desde los mismos orígenes del medio.

Palabras-clave: cine educativo, cine científico, cine higienista, cine de atracciones.

\section{O CINEMA CIENTÍFICO NA ARGENTINA DE PRINCÍPIOS DO SÉCULO 20: ENTRE A PEDAGOGIA E O ESPETÁCULO}

\section{Resumo}

Os primeiros filmes científicos argentinos foram, majoritariamente, produzidos por encomenda e rodaram nas mesmas companhias produtoras e com algumas das mesmas estratégias formais, temáticas e de mercado do cinema comercial. Assim, distante de constituir um material acessível apenas para especialistas, estes filmes foram projetados, com frequência, em salas comerciais, tiveram publicidades nas revistas da época e, por vezes, se tornaram sucessos de bilheteria. A partir de um recorrido por alguns dos principais filmes dessa temática, mostraremos que, assim como o cinema se converteu em parte integrante do mundo médico-científico da época, a ciência foi um componente importante da indústria do entretenimento desde as origens do meio.

Palavras-chave: cinema educativo, cinema científico, cinema higienista, cinema de atrações. 


\title{
THE SCIENTIFIC CINEMA IN ARGENTINA AT THE BEGINNING OF THE $20^{\text {TH }}$ CENTURY: BETWEEN EDUCATION AND ENTERTAINMENT
}

\begin{abstract}
The first scientific Argentine films were custom-made products shot by the same production companies, and with the same formal, thematic and market strategies that those of commercial cinema. Thus, far from being a material accesible only to specialists, these films were often exhibited in movie theatres, promoted in magazines and newspapers of the time and some of them even became bockbusters. From the analysis of some of the most relevant films on the subject, we will show that just as cinema became an integral part of the medical-scientific world of the time, so too science became an important component of the entertainment industry from the very same origins of the medium.
\end{abstract}

Key-words: educational cinema, scientific cinema, hygiene cinema, cinema of attractions.

\section{LE CINEMA SCIENTIFIQUE DANS L' ARGENTNE DU DEBUT DU VINGTIEME SIECLE: ENTRE L' ÉDUCATION ET LE SPECTACLE}

\section{Résumé}

Les premiers films scientifiques argentins étaient principalement des produits sur commande, qui ont été tournés dans les mêmes maisons de production et avec certains des mêmes stratégies formelles, thématiques et de marché du cinéma commercial. Ainsi, loin d'être un matériel accessible uniquement aux spécialistes, ces films ont été souvent projetés dans les salles de cinéma, ils ont été annoncés dans les magazines de l'époque, et parfois ils ont été devenus de véritables blockbusters. En analysant quelques-uns des grands films locaux de ce sujet, on montrera que si le cinéma a été une partie essentielle du monde médical et scientifique de l'époque, de la même manière, la science a devenue un élément important de l'industrie du divertissement depuis la naissance du cinéma.

Mots-clé: cinéma éducatif, cinéma scientifique, cinéma hygiéniste, cinéma d'attraction. 


\section{Instruir deleitando}

n la Argentina de fines del siglo 19 y principios del 20, la emergencia del cine estuvo estrechamente vinculada a la educación. A pesar de que ciertos sectores conservadores - entre ellos la Iglesia - observaron al nuevo medio con recelo, considerándolo una escuela del delito ${ }^{1}$, corruptora de los cuerpos y las mentes jóvenes, y criticaron los efectos hipnóticos y los contenidos inmorales de su vertiente más comercial; desde su misma llegada al país, las imágenes en movimiento captaron la atención de una gran parte de la intelectualidad argentina, que vislumbró su potencial pedagógico y las adoptó con entusiasmo en numerosos establecimientos educativos.

Entre ellos se encontraban importantes colegios, como el Nacional Buenos Aires, que construyeron salas específicamente concebidas para la proyección cinematográfica o que, como el Otto Krause, incorporaron en sus programas talleres de cinematografía donde se enseñaban los principios básicos de esta nueva técnica ${ }^{2}$. Algunos de los más acérrimos defensores de la utilización del cine como herramienta didáctica, como el escritor y crítico de cine Horacio Quiroga, aseguraban que este medio permitiría un acercamiento insuperable al mundo real y democratizaría la cultura ${ }^{3}$. Sin embargo, fueron los médicos, imbuidos de un espíritu positivista que se instaló fuertemente en el contexto de la cultura finisecular vernácula, los que primero comprendieron la importancia del cine como auxiliar pedagógico.

Los primeros films científicos fueron mayoritariamente productos por encargo, que se rodaron en las mismas compañías productoras que por entonces estaban dando forma al incipiente cine nacional. Concebidas en el seno de la naciente industria fílmica local, estas películas pioneras estuvieron sujetas a algunas de las mismas estrategias formales, temáticas y de mercado del cine comercial. En efecto, la potencialidad del cine como herramienta educativa, no pasó desapercibida para los primeros empresarios y cineastas, que pronto se encontraron buscando nuevas tácticas para desarrollar las capacidades pedagógicas del medio y acercar estos films a las masas. El empresario vasco Julián de Ajuria, productor, hacia la época del Centenario, de algunas de las primeras películas de ficción argentinas y director, por gran parte del período silente, de la Sociedad General Cinematográfica - por entonces una de las más importantes distribuidoras de cine norteamericano en el país - escribió en el prólogo de su enciclopédico libro El cinematógrafo, espejo del mundo, un valioso testimonio que pone en evidencia el espíritu que primó en estos tempranos films educativos:

Se reúnen hoy todas las artes en esta Institución del cinematógrafo, cuyo lema es "Instruir deleitando"; están sujetas a un cálculo mercantil para que sus ingresos alimenten las fuerzas vivas que han de darle forma y expansión, y poder proyectar en sus imágenes todos los conocimientos humanos que circundan el globo; a fin de alcanzar sus propósitos y el grado de cultura a que

\footnotetext{
${ }^{1}$ Véase por ejemplo Aquí y allí, La Película, n. 488, 28 ene. 1926, p. 5.

${ }^{2}$ Véase el Álbum de la Industria Argentina, Buenos Aires, Unión Industrial Argentina, 1923.

${ }^{3}$ Quiroga escribió una serie de artículos defendiendo las potencialidades didácticas del cine que fueron publicados en diversas revistas de interés general de la época. Entre ellos se destaca El cine en la escuela: sus apologistas, Caras y caretas, n. 1116, 21 feb. 1920, s.n.; El cine educativo. Patagonia, Atlántida, n. 226, 3 ago.
} 1922, s.n. y El cine nacional, El Hogar, n. 973, 8 jun. 1928, s.n. 
está destinada la misión del Cinematógrafo [...]. El cine es ya una de las fuerzas de nuestra época, el mejor medio de difundir ideas y sentimientos políticos y culturales, un instrumento de expansión para el comercio y las industrias, un vehículo que nos pone al alcance de todos los pueblos [...] siempre que lo empleemos para el fin con que ha nacido: instruir deleitando, con arte, humor, moral y ciencia. (1946, p. 17)

La idea de un cine que instruye deleitando es fundamental para comprender estas primeras películas científicas que, lejos de constituir un material accesible sólo para una elite de estudiantes y eruditos, se proyectaron con frecuencia en salas comerciales, se publicitaron y reseñaron en las revistas cinematográficas de la época y en ocasiones se convirtieron en verdaderos éxitos de taquilla. Si en un principio educación y entretenimiento parecían representar dos polos antagónicos e irreconciliables, lo cierto es que, como sugiere Lacey Langston, "film was a central part of the scientific and medical world in the early twentieth century, and science was a prominent part of the entertainment industry both thematically and educationally" (2010, p. 2).

A partir de un recorrido por algunos de los principales films de esta temática realizados en la Argentina durante el período silente (1896-1933), en el siguiente ensayo intentaremos poner en evidencia cómo estos cruces entre educación y espectáculo estuvieron presentes en el cine científico desde los mismos orígenes del medio. Teniendo en cuenta que la mayor parte del material fílmico de este tipo se encuentra hoy perdido, nos detendremos más detalladamente en aquellas películas que han sobrevivido en forma total o parcial hasta nuestros días, intentando reconstruir, a través de materiales extra-fílmicos, algunos de los films desaparecidos que resulten de mayor interés para nuestro análisis.

\section{Operaciones quirúrgicas: educación científica y cine de atracciones}

Frank Kessler (2003) ha sugerido que los primeros años del cine pueden dividirse en tres etapas caracterizadas por un diferente y particular funcionamiento del dispositivo cinematográfico. En primer lugar, un primer período de novedad tecnológica, determinado por la emergencia del cine como dispositivo espectacular, en el que la reproducción del movimiento y el paradigma de la captación/restitución propios de este medio constituyen la atracción principal del espectáculo fílmico. A continuación, una segunda etapa caracterizada por un predominio del cine como dispositivo de lo espectacular, en el que las atracciones ${ }^{4}$ se

\footnotetext{
${ }^{4}$ El concepto de cine de atracciones fue acuñado por los historiadores del cine Tom Gunning y André Gaudreault para englobar a una considerable parte de la producción cinematográfica previa a 1906 cuyo rasgo distintivo es su componente exhibicionista, su evidente conciencia de la presencia de un espectador al que se interpela de forma directa y explícita. Según los autores, las atracciones sirven para describir a este particular modo de representación fílmico, caracterizado por la predominancia de elementos espectaculares y atracciones visuales discontinuas, que funciona como una suerte de antítesis del principio dominante del cine institucional posterior: la narración. Sin embargo, como reconoce el mismo Gaudreault, esta oposición no es nunca tajante y ambas modalidades representativas colaboran y funcionan en una constante tensión en gran parte de los films de este período. El cine de atracciones alude, además, a una particular relación con el espectador. En contraste con el carácter voyeurista del cine narrativo, la atracción pone en evidencia la implícita presencia del espectador, "está ahí para ser vista [y] en sentido estricto [...] existe sólo con el propósito de hacer alarde de su visibilidad" (Gunning, 1995, p. 179). Por último, este término sugiere un novedoso modelo de periodización que señala dos fases distintivas para el cine de los primeros tiempos: un primer período determinado por el predominio de las atracciones y un segundo período, iniciado alrededor de 1906 - aunque en países como la Argentina se extendió considerablemente más allá de esa fecha, definido por la preponderancia de la integración narrativa.
} 
convierten en el plato principal del espectáculo cinematográfico. Por último, un tercer período, en el que la utilización del dispositivo se ve trasformada por una creciente tendencia hacia la construcción de relatos, donde los elementos narrativos pasan a primer plano y las atracciones - sin desaparecer del todo - se convierten en un elemento más del espectáculo fílmico. ${ }^{5}$ Si bien esta periodización fue concebida originalmente para el cine comercial, como veremos en las siguientes páginas, el modelo resulta igualmente operativo para analizar gran parte de los films científicos del mismo período.

No es casual que las películas más antiguas que hoy se conservan en la Argentina ${ }^{6}$, las Operaciones del doctor Posadas (Enrique Lepage y Cía, ca. 1899), documenten dos intervenciones quirúrgicas realizadas en el país hacia principios del siglo 20. Como sostiene Tom Gunning,

the aesthetic of attractions developed in fairly conscious opposition to an orthodox identification of viewing pleasure with the contemplation of beauty. [...] this atracction to the repulsive was frequently rationalised by appealing to [...] intellectual curiosity. Like the early film exhibitions, freak shows and other displays of curiosities were described as instructive and informing. (1994, p. 124)

En efecto, este film es básicamente un registro documental de dos operaciones quirúrgicas realizadas a principios del siglo 20 por el cirujano argentino Alejandro Posadas. En la primera de ellas se muestra una intervención de hernia inguinal y en la segunda Posadas practica uno de sus mayores logros médicos: la extirpación de un quiste hidatídico de pulmón, en la que utiliza una novedosa técnica de arponamiento pulmonar que luego llevaría su nombre (figura 1). Además de un talentoso cirujano - que a pesar de su temprana muerte tuvo una destacada actuación en el campo médico local -, Posadas fue un notable docente que incorporó tempranamente láminas ilustrativas y otros auxiliares visuales en sus clases magistrales.

${ }^{5}$ Aunque lógicamente este modelo de periodización no puede ser transplantado en forma directa a la cinematografía argentina, donde las transformaciones señaladas se dieron en forma más lenta y mucho menos abrupta, los criterios historiográficos propuestos por estos autores constituyen una herramienta útil y factible de ser matizada y amoldada a la realidad local. De acuerdo con el mismo Gaudreault, el modelo no pretende ser una taxonomía rígida en la cual puedan insertarse de manera unívoca todos los films producidos en este período, sino que, por el contrario, tiene el potencial de convertirse en un instrumento flexible y adaptable a diversas cinematografías (Gaudreault, 2004, p. 44).

${ }^{6} \mathrm{Si}$ bien no se conoce con certeza la fecha exacta de las filmaciones de Posadas, el hecho de que el médico murió en Paris en 1902 y que desde 1901 padecía una osteoartitis tuberculosa que le impedía operar permite suponer el rodaje tuvo lugar entre 1899 y 1900, es decir apenas unos meses después de las celebres operaciones del dr. Eugène-Louis Doyen en Francia, hoy consideradas los primeros documentos fílmicos de una intervención quirúrgica en el mundo. 
Figura 1 -

Dos fotogramas de Operaciones del dr. Posadas.
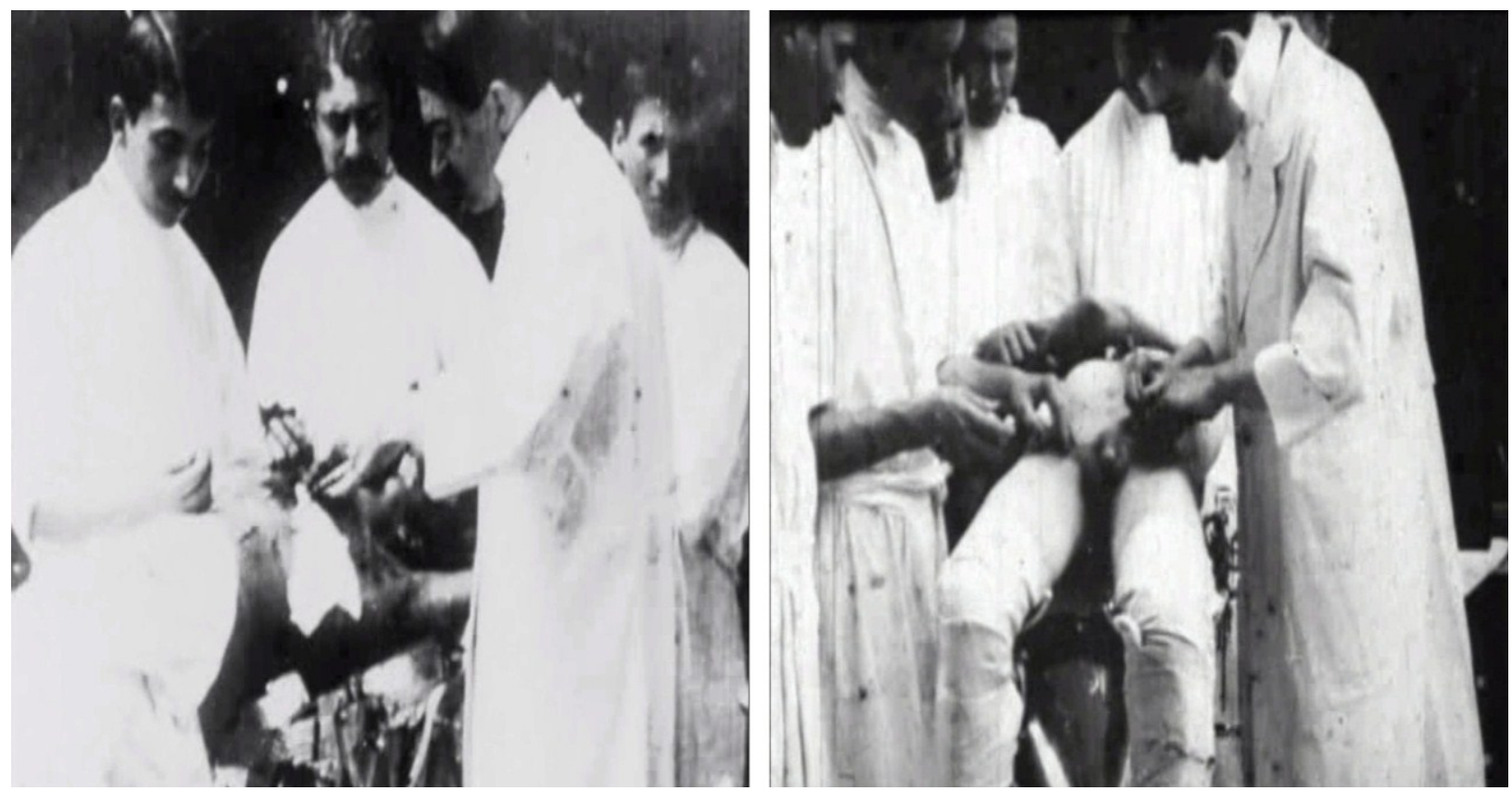

Fonte: Eugenio Py (1899).

Hacia 1899, entusiasmado por las novedosas vistas cinematográficas, le encargó a Eugenio Py, camarógrafo estrella de la flamante Casa Lepage - la primera productora y distribuidora cinematográfica del país - que documentara dos de sus intervenciones quirúrgicas, con el único propósito de utilizarlas como material didáctico en sus conferencias médicas. Este tipo de films, rodados con extrema dificultad, constituían un verdadero desafío para la labor médica ya que, por necesidades propias de la exposición, debían ser realizados al aire libre bajo la enceguecedora luz del mediodía y en menos de cuatro minutos - duración de la bobina de película - poniendo en riesgo la misma tarea quirúrgica en pos del afán educativo.

Destinado originalmente a un público especializado, el film pronto se volvió parte de los catálogos de actualidades, integrándose sin conflictos con las bodas, los funerales, los actos cívicos y las revistas militares, entre otras temáticas que nutrieron las primeras proyecciones públicas del cinematógrafo Lumière. Así, en el número de mayo de 1904, la Revista Fotográfica llustrada del Río de la Plata, editada por la Casa Lepage, anuncia entre las vistas a la venta un rollo de 50 metros titulado Operaciones quirúrgicas, que contenía muy posiblemente las dos cirugías realizadas por Posadas; y poco después, en el número de julio de 1905 se agrega una nueva cinta titulada Operaciones del dr. Flores, sobre la que no existen más datos. 
El catálogo de Lepage incluyó también films científicos extranjeros. Por ejemplo, en junio de 1904, se anuncia la venta de cuatro rollos de 30 metros cada uno, titulados Operaciones del Dr. Doyen, que incluían "una extirpación de un quiste en el vientre, una intersección abdominal, una trepanación del cráneo y la resección de una rodilla" (Revista Fotográfica llustrada del Río de la Plata, n. 130, jun; 1904, s.n.).

Eugène-Louis Doyen, uno de los cirujanos más famosos de la época y autor de las más tempranas filmaciones de operaciones quirúrgicas en el mundo, fue de hecho protagonista de uno de los primeros juicios de copyright de la historia del cine, cuando uno de sus más famosos films, Separation des soeurs siamoises Rodika et Dodika (1898) fue objeto de una distribución comercial como la ofrecida por la Casa Lepage. El médico francés, que encargó las filmaciones a los operadores Clément Maurice y Ambroise-François Parnaland, exhibió públicamente sus películas en la Exposición Universal de París, ganándose tanto la admiración de grandes personalidades, como el zar de Rusia o el emperador de Alemania, como el desprecio de muchos de sus colegas que pensaban que con estas cintas se violaba la privacidad del paciente y la integridad médica. Sin embargo, el escándalo estalló cuando Parnaland secretamente copió algunos de estos films - entre ellos el de la separación de las siamesas y las impresionantes craneotomías - y los vendió a la empresa Pathé, para que los distribuyera y exhibiera a nivel mundial entre públicos ávidos de emociones fuertes. El cirujano inició acciones legales contra su operador y contra Pathé, que en 1905 fueron finalmente obligados a pagar una importante indemnización ${ }^{7}$. A pesar del fallo favorable, Doyen fue inmediatamente bautizado por gran parte de la comunidad científica francesa como el Barnum de la cirugía, en irónica referencia al célebre empresario circense norteamericano.

La cirugía - ciencia todavía en sus albores - los cuerpos desnudos, fragmentados o deformados - por entonces parte integral de otros espectáculos masivos como el circo, los gabinetes de curiosidades o los freak shows - el accionar del médico a cargo - ubicado a medio camino entre la ciencia y la magia - fueron algunos de los elementos que volvieron a estos films atractivos para el público masivo. Aunque no existe demasiada información sobre el ámbito y la frecuencia de exhibición de estas cintas en la Argentina, el hecho de que formaran parte de los catálogos de venta de compañías comerciales como la Casa Lepage, junto a diversos tipos de actualidades locales e internacionales e incluso compartiendo su espacio con algunos de los incipientes films de ficción, sugiere que estas películas científicas también fueron parte integral de las primeras proyecciones cinematográficas locales.

Las Operaciones del Dr. Posadas no fue un ejemplo aislado sino, más bien, el primer exponente de un tipo de film científico que tuvo una sostenida continuidad, por lo menos durante las primeras dos décadas del período silente. Así, a los ya mencionados se agregan, en los años subsiguientes, otros interesantes ejemplos. Entre mayo y junio de 1920, las revistas La Película y Excelsior incluyen en sus páginas, varias noticias sobre la preparación y posterior estreno de un film científico titulado Técnica general para las amputaciones cineplásticas, nuevo procedimiento del dr. Guillermo Bosch Arana, realizado por la empresa

${ }^{7}$ Para más información sobre este juicio véase Lefebvre (1994 y 1995). 
editora F.I.F.A, propiedad del camarógrafo y productor Pío Quadro. Aunque el film hoy se encuentra perdido, una breve reseña publicada en junio de 1920 en la revista La Película da somera cuenta de su contenido:

El Dr. Bosch Arana, mediante la colaboración del operador cinematográfico, señor Pío Quadro, ha confeccionado una película de carácter científico, en la que ha puesto de manifiesto dicho facultativo la importancia de sus trabajos sobre amputaciones. En la cinta de referencia, cuya fotografía es de una nitidez absoluta, el observador puede apreciar el ingenio que en materia de ortopedia ha desarrollado el doctor Arana, quien aplicando a los miembros que han sufrido amputaciones una serie de aparatos, bien sencillos por cierto, ha suplido fácilmente las partes cortadas. (La Película, n. 195, 17 jun. 1920, p. 19)

El film fue rodado por encargo de la Sociedad Médico Argentina y estaba protagonizado por el Dr. Bosch Arana, profesor de las cátedras de Medicina Operatoria y Técnica Quirúrgica y vicedecano de la Facultad de Ciencias Médicas de la Universidad de Buenos Aires, fundador de la primera escuela de Instrumentación Quirúrgica y del Instituto de Cirugía Experimental, y miembro del consejo directivo del colegio llse, que seguramente concibió el film como material didáctico para sus clases y conferencias. Sin embargo, una nota aparecida el 20 de mayo de 1920 en La Película sugiere que esta cinta trascendió el ámbito de los claustros académicos. Con el título de Películas instructivas, la crónica informa:

Está siendo un verdadero filón para nuestros operadores las películas instructivas y comerciales. Así no pasa día que no nos anuncien la terminación de uno de estos films. Últimamente se exhibió una hecha por el señor Pío Quadro, para la Sociedad Médica Argentina que constituyó un verdadero éxito. (La Película, n. 191, 20 mayo 1920, p. 15)

En efecto, la realización de películas educativas fue una veta productiva, que muchas de estas incipientes compañías nacionales supieron explotar con buenos resultados ${ }^{8}$. Poco después, en 1925, la Colón Film - otra gran empresa productora de la época, propiedad del fotógrafo, director y operador Luis Scaglione - anuncia entre sus estrenos el film Operaciones del Instituto de Clínica Quirúrgica (Luis Scaglione, 1925), un film de carácter didáctico, hoy también lamentablemente perdido. Esta compañía, que en las publicidades decía ser la "única argentina que contaba con una galería y teatro de pose", se dedicaba con frecuencia a la producción y edición de películas de ficción pero, sin duda, su verdadero negocio estaba en la realización de actualidades, films comerciales, industriales, familiares y educativos como el mencionado en el anuncio. Teniendo en cuenta la más bien modesta producción de films de ficción vernáculos durante ese período, ésta debió ser una realidad para muchas de las empresas fílmicas locales, que pudieron sobrevivir gracias a esta actividad paralela y absolutamente compatible con la estrictamente comercial.

${ }^{8}$ Ese mismo año, en una publicidad aparecida también en La Película, la misma Fifa anuncia entre sus especialidades la realización de trabajos de índole científica y nombra la película de Bosch Arana como referencia. Véase La Película, n. 194, 10 jun. 1920, p.17. 
Otro interesante ejemplo de este tipo es el film Instituto Modelo de Clínica Médica, realizado hacia 1922 por el Establecimiento Cinematográfico Martínez y Gunche, una de las compañías más importantes del período y productora del que quizás sea el film nacional más exitoso de la etapa silente, Nobleza Gaucha - Eduardo Martínez de la Pera y Ernesto Gunche, 1915. Contrariamente a los hasta ahora analizados, en este film hay una voluntad comercial implícita que se evidencia en su carácter híbrido y en la presencia de un doble espectador modelo, que permite que la película sea leída tanto como un film de actualidades o como una cinta científico-educativa.

Según informan los intertítulos iniciales, Instituto Modelo de Clínica Médica fue un obsequio del Ingeniero Rodolfo A. Morales y señora al Dr. Luis Agote en agradecimiento al oportuno diagnóstico clínico de su hija de catorce años "gravemente atacada de apendicitis perforada [y] [...] milagrosamente restituida a la vida", en una difícil intervención quirúrgica realizada en el hospital que da título al film. Con un concepto tanto informativo-publicitario como científico-didáctico, el film puede dividirse claramente en dos partes. En la primera sección se documentan las diferentes facetas del funcionamiento de esta institución ejemplar, fundada en 1914 por el mismo Agote, deteniéndose en su pensada arquitectura, sus pulcras salas de internación, su competente equipo médico y su programa educativo, con cátedras y lecciones prácticas a cargo de los diferentes especialistas de la clínica, entre otros aspectos.

Sin embargo, justo en la mitad del film, la cámara se sumerge en el interior del quirófano del Dr. Alberto Galíndez para capturar minuciosamente una operación de úlcera gástrica en un internado. Aquí el descriptivo plano general, que domina al primer segmento, da paso a un mucho más didáctico primer plano y los intertítulos abandonan su carácter divulgador por un discurso pedagógico, que describe minuciosamente cada uno de los pasos de la cirugía con un lenguaje técnico y preciso (figura 2). Concluida la intervención, el film vuelve al tono ligero, informativo y publicitario de la primera parte y continúa registrando la actividad del hospital y de su director, Luis Agote, que hacia el final parte a Europa, dejando la Institución temporalmente a cargo de su discípulo Raúl Novaro. 
Figura 2 -
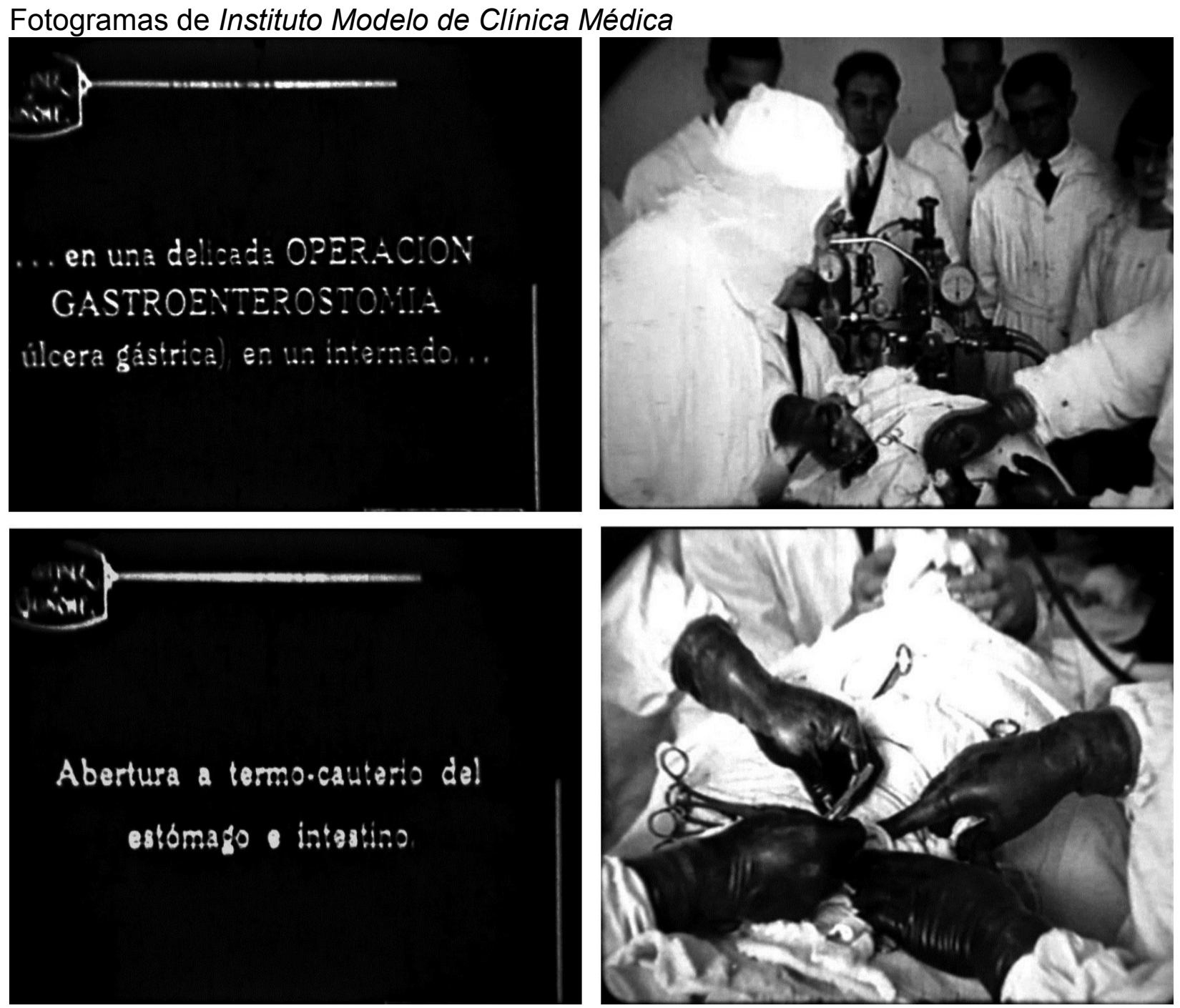

Fonte: Eduardo Martínez de la Pera y Ernesto Gunche, 1922.

Como el inicio del film, este final deja perfectamente claro que Agote - entonces uno de los médicos más reconocidos de la época por haber logrado en 1914 la primera transfusión exitosa de sangre citrada en humanos - es el principal protagonista del film. La presencia de estos reputados profesionales, figuras emblemáticas del mundo médico-científico de la época es, como vimos, una constante en este tipo de películas. La idea de que la personalidad del cirujano tenía un rol didáctico fundamental en los films, había sido incluso defendida por pioneros del cine científico como el mencionado Doyen:

As Doyen repeated endlessly, his films should above all demonstrate the surgeon's "personality", defined by the latter's undistracted "concentration" and "self-confidence" - features that a scientific paper or a lecture, he argued, would never adequately demonstrate. According to Doyen, demonstrating the surgeon's self-confident personality while operating was as important as demonstrating any particular surgical technique itself. [...] One could not understand a new surgical procedure by reading about it, or even by watching 
it being performed by any other surgeon: one had to see the procedure being carried out by its own creator. In other words, which once again accounts for why his films didn't limit themselves to framing the surgeon's hands, "one had to see the master". (Baptista, 2005, p. 45)

Este foco en la figura del profesional hizo que los médicos adoptaran en estas películas un papel cercano al de las estrellas de cine, dotando indirectamente al film de otro elemento espectacular. Como sugiere Lacey Langston, "the kinds of terms Doyen uses to describe the surgeon's role, such as 'personality' and 'self confidence' could easily be attributed to a performer" (2010, p. 13). De hecho, mucho antes de la aparición del cine, los médicos demostraban a sus discípulos las diferentes técnicas quirúrgicas en los llamados anfiteatros anatómicos, salas especialmente diseñadas para la enseñanza de la cirugía y con una arquitectura muy similar a la de los teatros convencionales, donde no era extraño, además, que concurrieran los curiosos a presenciar las operaciones y disecciones como forma de espectáculo. No es casual, entonces que en muchos de estos primeros films científicos, el cirujano muestre un claro entendimiento de su rol performativo. La postura de sus manos y su cuerpo en el espacio, el posicionamiento de sus asistentes, demuestran una absoluta conciencia del espectador al que está destinado. Como exponentes del cine de atracciones, estas películas se dirigen al público en forma directa, lo saben presente y buscan despertar y satisfacer rápidamente su curiosidad visual mediante un conciente y frontal acto de display.

\section{Cine e higienismo: el arte de llevar la ciencia a las masas}

No todos los films científicos realizados en el país fueron originalmente concebidos para un público especializado. Hacia principios de la década de 1920, impulsadas por el higienismo que venía desarrollándose como práctica institucionalizada desde fines del siglo 19, comenzaron a aparecer una serie de películas que intentaron llevar las enseñanzas de la ciencia a las masas. Esta corriente hizo de la higiene un tema prioritario y encontró en la falta o precariedad de ésta una gran parte de los males de la Argentina de la época.

En los inicios del siglo 20, el fenómeno inmigratorio - que para entonces había alcanzado una dimensión sin precedentes -, la ascendente tasa de desocupación, el desordenado crecimiento de las áreas urbanas - que generó hacinamiento y desaseo en las viviendas populares -, la carencia de dispositivos sanitarios y de salubridad y el recrudecimiento de las tensiones políticas y populares, transformaron a la higiene de un problema público en uno social. A pesar de su inscripción política heterogénea, los impulsores del higienismo en la Argentina coincidieron en la importancia de acudir a la ciencia para comprender las manifestaciones de estos múltiples problemas y darles debida respuesta. La salud, las instituciones de asistencia, pero sobre todo la educación fueron los principales pilares en los que se apoyaron los representantes de esta corriente. Si bien todos los medios de comunicación fueron funcionales a su plan educativo, el cine, por su alcance masivo y por la democrática accesibilidad de su lenguaje, se convirtió en un instrumento ideal de divulgación científica, sobre todo entre la creciente población de inmigrantes que, de esta manera, no necesitaban conocer a fondo el idioma para entender el mensaje. 
El surgimiento del cine higienista fue acompañado, así, por el desarrollo de una serie de proyectos institucionales. Para la década de 1920, por ejemplo, el Instituto de Higiene contaba ya con una política de extensión universitaria que se valió de variados recursos, entre los que figuraba el dictado de conferencias periódicas con "proyecciones luminosas, cintas cinematográficas, diagramas, dibujos, etc., en las escuelas, bibliotecas, locales sociales [...] [para divulgar] los principios básicos de la profilaxis y de la higiene escolar y especialmente contra la tuberculosis" (Túmburus, 1926, p. 95).

El Cuerpo Médico Escolar y el Instituto de Higiene trabajaron conjuntamente, fomentando la realización de películas exclusivamente pensadas para el ámbito educativo en sus diferentes niveles y que, "en oportunidades, reclamaban el consentimiento escrito de los padres o tutores para que los jóvenes pudiesen verlas"9 (Sánchez, 2007, p. 449). El Consejo Nacional de Educación, por su parte, inició una activa política de adquisición de films científicos e higienistas para utilizar como material didáctico en las escuelas del país. Uno de esos films fue La mosca y sus peligros, a cuyo estreno asistieron, de acuerdo a la revista La Película, "las autoridades superiores del Consejo Nacional de Educación, [...] interesadas en adquirir esta película para proyectarla en las escuelas de su dependencia" (La Película, n. 189, 6 mayo 920, p. 9). La publicación agregaba que "en las esferas oficiales el admirable trabajo de la casa Martínez y Gunche ha causado excelente impresión y se habla de adquirir la cinta "La mosca y sus peligros" como asimismo, encargar a la citada empresa otros trabajos de esa índole, para proyectar en las instituciones de enseñanza" (p. 9).

La mosca y sus peligros es, sin duda, uno de los hitos del temprano cine científico argentino. Estrenada en función privada el 27 de marzo de 1920 en el Splendid Theatre de Buenos Aires ante un numeroso público de especialistas, entre los que se encontraba el intendente de la ciudad, José Luis Cantilo, varios directores de los principales hospitales porteños y otras destacadas personalidades del mundo universitario ${ }^{10}$, la película estaba producida por el Establecimiento Cinematográfico Martínez y Gunche, la misma empresa responsable de la analizada Instituto Modelo de Clínica Médica. Esta fue, quizás, la productora argentina que más se especializó en films de carácter científico durante el periodo silente. Ya en 1919, la revista Excelsior afirmaba que la compañía había sido la primera "en filmar películas instructivas en la Argentina, siendo la más importante una de botánica que es digna de figurar al lado de las norteamericanas de la casa Pathé"11 (Excelsior, n. 259, 26 feb. 1919, p. 250).

A pesar de que este artículo informaba la intención de la empresa de encauzar la explotación de sus películas a la manera norteamericana, es decir encargándose únicamente de la edición, para 1920 los avisos publicitarios de la firma no sólo ofrecían "vistas del país educacionales y científicas" sino que manifestaban contar con un "laboratorio especialmente

\footnotetext{
${ }^{9}$ No existe mucha información sobre los films realizados por el Instituto de Higiene. Norma Sánchez (2007) y Héctor Palma (2002) mencionan en sus investigaciones los siguientes títulos: Como comienza la vida, Madres educad a vuestros hijos, La sifilis, La defensa social contra la prostitución y Protección social femenina. Sin embargo, ninguno de los dos provee ninguna información sobre los años de producción de los films, los profesionales involucrados o los contenidos, que sólo pueden intuirse vagamente de los títulos.

${ }^{10}$ Véase Excelsior, n. 313, 10 mar. 1920, p. 1659 y La Película, n. 186, 15 abr. 1920.

${ }^{11}$ No se conocen más datos sobre esta película hoy también perdida.
} 
montado para Cine-micrografía" (Excelsior, número extraordinario, marzo de 1920, p. 17571758). En efecto, el Establecimiento Cinematográfico de Martínez y Gunche fue pionero en la utilización de esta técnica en el país e incluso fue responsable del diseño y ensamblaje de todos los dispositivos ópticos utilizados para la realización de estos films. La mosca y sus peligros fue la primera de una serie de films cinemicrográficos realizados por la empresa, que de acuerdo a las publicaciones de la época, incluyó por los menos otras dos películas higienistas: una sobre el mosquito como agente transmisor de la fiebre palúdica y otras enfermedades endémicas ${ }^{12}$ y otra sobre el cáncer, que contó con el asesoramiento del dr. Ángel Roffo, reconocido especialista argentino en oncología.

Contrariamente a estos dos últimos films, hoy lamentablemente perdidos, La mosca $y$ sus peligros es una de las pocas películas científicas realizadas durante este período que ha sobrevivido hasta nuestros días, hecho que permite un análisis más exhaustivo de sus contenidos. Realizado poco después de la pandemia de gripe española que azotó al país durante 1918 y 1919, este mediometraje recoge el clima de inquietud y ansiedad xenófoba que acompañó a esa plaga, cuyo origen se asoció inmediatamente a las crecientes oleadas de inmigrantes que arribaban al país. El film, que contó con el asesoramiento de un ignoto médico de apellido Bárbara ${ }^{13}$, está investido de un discurso científico de autoridad que acompaña a cada una de las imágenes mostradas. Ya en el primer intertítulo, se informa al espectador que el principal objeto de la película "es divulgar entre el público, conocimientos que en general son sólo del dominio de los investigadores" (Excelsior, n. 310, 18 feb.1920, p. 1599). De esta manera, el documental comienza por presentar una descripción filogenética de la mosca, deteniéndose en sus particularidades orgánicas y biológicas.

Un científico y su ayudante observan detenidamente en el microscopio las diferentes partes del insecto, dando cuenta de su particular funcionamiento, a la vez que, desde los intertítulos, se explican detalladamente los diversos pasos del propio método de estudio. Sin embargo, hacia la mitad del film, cuando se comienza a ahondar en los efectos nocivos que la mosca produce en la salud humana, en su rápida e incontenible reproducción y en las diversas formas en las que ésta transmite enfermedades, el objetivo discurso didácticocientífico inicial da paso a un registro más cercano a la literatura fantástica o de terror, que a través de la cinemicrografía convierte al insecto en un verdadero monstruo e introduce algunas de las imágenes más espeluznantes del film. Así, luego de mostrar amplificadas en el microscopio las múltiples bacterias que anidan en las patas de las moscas y la velocidad con la que estás se multiplican, la cámara sigue a los repugnantes insectos desde el sucio baño de un conventillo al biberón de un inocente bebé, previniendo sobre los diversos males que éstos transmiten a los infantes. Como si esto no fuera suficiente, la advertencia es seguida por una sucesión de desoladoras imágenes que muestran a lactantes y niños pequeños sufriendo de múltiples afecciones, desde intoxicaciones alimenticias y enfermedades intestinales hasta poliomielitis o meningitis (figura 3).

${ }^{12}$ En este film, que mostraba las acciones nefastas de ese insecto en el norte del país, Martínez y Gunche utilizaron estufas para criar a los temibles mosquitos y reproducir en estudio su proceso generativo y los diferentes estadios de su desarrollo. Véase La Película, n. 194, 10 jun. 1920, p. 15.

${ }^{13}$ Véase Excelsior, n. 310, 18 feb. 1920, p. 1599. 
Figura 3 -

Fotogramas de La mosca y sus peligros.
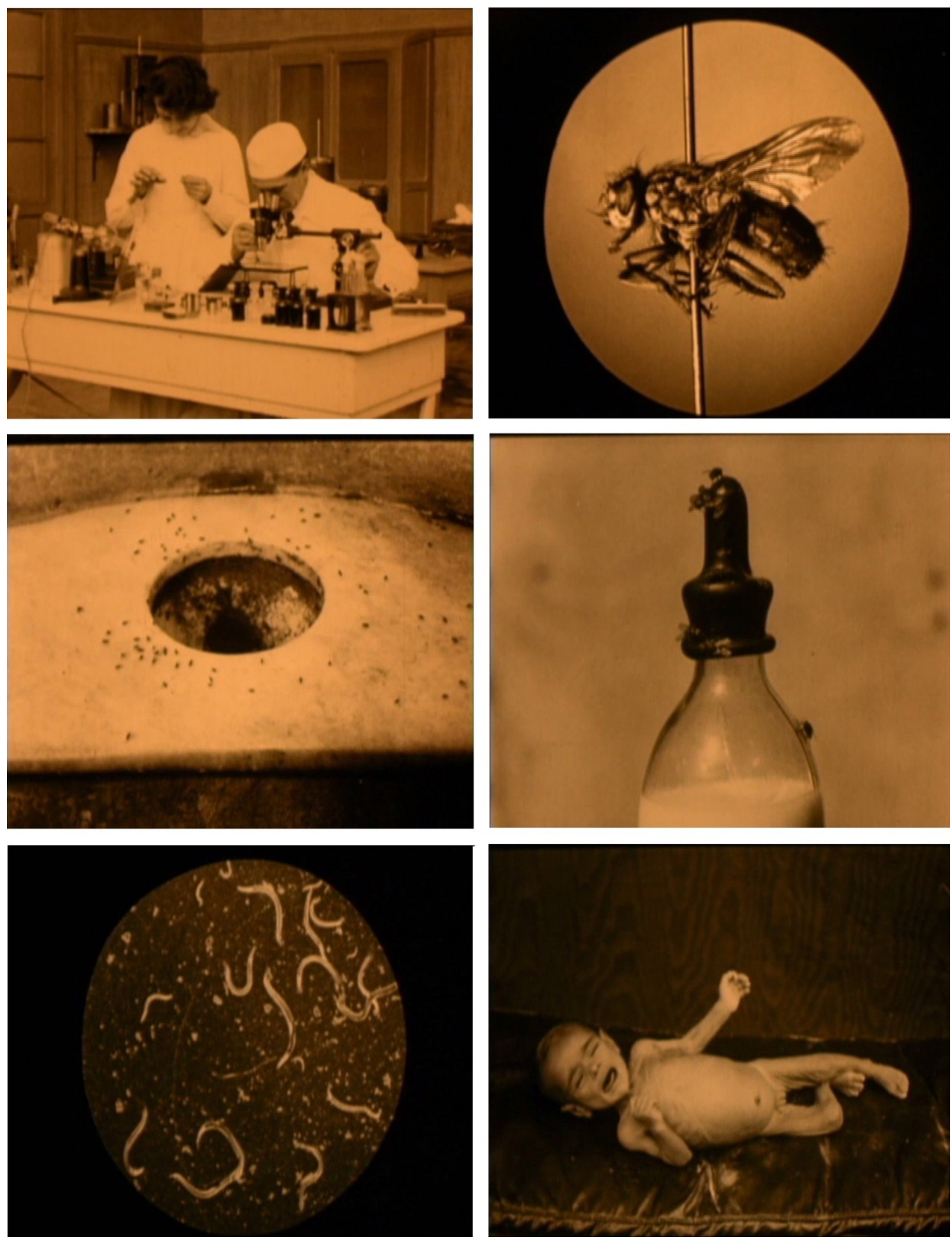

Fonte: Eduardo Martínez de la Pera y Ernesto Gunche, 1920. 
Como afirma Matt Losada,

instead of a more objectively scientific description, the presentation underlines the specifically horrifying aspects of the fly. [...] The microphotography makes bacteria visible, obliging the viewer to recognize the inability of his or her corporeal sensorium to perceive this infectious dimension, generating anxiety regarding the same germs that the film goes on to clearly associate with immigrant and other economically disadvantaged populations. [...] The barely visible (including flies, their snouts, claws and eggs) is magnified to a scale that makes manifest its most horrifying qualities, while the invisible (bacteria and other causes of disease) is made visible. (2012, p. 467 y 472)

En efecto, esas imágenes terroríficas y sensacionalistas - que vulneran constantemente la supuesta imparcialidad científica del film -, pero sobre todo las asombrosas y cuasiteratológicas fotomicrografías de insectos y bacterias transforman a la película en un producto a medio camino entre la educación y el espectáculo.

Hacia fines del siglo 19, los aportes de Louis Pasteur y Robert Koch en materia de bacteriología habían sido fundamentales para aclarar aspectos conceptuales de la medicina de la época y dar clara cuenta de las formas de contagio y los métodos y prácticas de prevención. La fotomicrografía y la cinemicrografía fueron, sin duda, dos instrumentos privilegiados para llevar estas enseñanzas de la ciencia bacteriológica tanto a los especialistas como al espectador común. Sin embargo, como vimos, la utilidad didáctica de estas novedosas técnicas se vio rápidamente opacada en estas películas por su creciente potencial espectacular.

Para 1920, la cinemicrografía contaba ya con exitosos exponentes fílmicos internacionales, como los que integraron la serie El mundo oculto (The unseen world), realizados en los primeros años del siglo 20 por el naturalista británico Francis Martin Duncan para el productor Charles Urban, o los concebidos hacia 1910 y en colaboración con la Casa Pathé, por el científico francés Jean Comandon. Ese cine de lo invisible, con sus sorprendentes vistas microscópicas de insectos, gérmenes y demás microorganismos, fue otro de los géneros del cine de atracciones, que mezcló sin conflictos educación y entretenimiento. Como afirma Kirsten Ostherr, "[these] films [...] partook of an aesthetic of astonishment," in which pleasure revolved around the fascination of seeing previously unimaginable views, including enlargements of bacteria and other revelations of the invisible, disease-carrying microbes that surround (2002, p. 4).

En este sentido, el carácter híbrido de La mosca y sus peligros se replica en el aspecto receptivo. Las crónicas de la época sostienen que el film fue exhibido durante años en proyecciones matinales instructivas para niños en edad escolar ${ }^{14}$ pero también dan cuenta de un éxito comercial que excedió al ámbito educativo. Así, en marzo de 1920, poco antes de su estreno oficial, la revista Excelsior señalaba que se trataba de "una labor de divulgación científica motivada por la afirmación corriente de que en el país no es posible hacer lo que se

${ }^{14}$ Véase Peña (2012, p. 32). Hist. Educ. [Online] 
hace en el extranjero" (Excelsior, n. 312, 3 mar. 1920, p. 1641) y vaticinaba que su exhibición interesaría "a legos y profanos, pues en su ejecución se ha hecho derroche de ingenio y paciencia y se ha logrado un conjunto interesante que llena completamente el objeto a que está destinada" (p. 1641). Pocos días después, la publicación ratificaba esta idea:

Siempre se ha afirmado que las cintas cinematográficas científicas eran de pobre interés, dado que debían ser cortas en metraje para no fatigar al público; que era muy difícil que llenaran completamente su objeto; primeramente porque con ellas cuesta demostrar con claridad sin llegar al exceso de detalles pasados é inútiles de que se peca generalmente, que no entretenía ni instruían y sólo se lograba aburrir. La primera cinta de ésta índole de industria nacional es la que presentarán el sábado próximo en el Splendid Theatre [...] titulada: "La mosca y sus peligros". [...] La confección de esta cinta, demuestra las posibilidades que permite la cinematografía. Afirman Martínez y Gunche que están hoy en condiciones de producir cintas cinematográficas para la enseñanza elemental, secundaria y superior. La practica adquirida en un año y medio que se ha empleado en la confección de ésta cinta, coloca a la cinematografía nacional en condiciones de producir cuanto sea necesario para la enseñanza de la parasitología, bacteriología, zoología y demás ciencias experimentales. (Excelsior, n. 313, 10 mar. 1920, p. 1659)

Luego del estreno, la revista Imparcial Film anunció, por su parte, que con La mosca y sus peligros, "primera película científica bien hecha en el país, Martínez y Gunche [habían] [...] obtenido un señado (sic) triunfo" (Imparcial Film, n. 55, 11 mayo 1920, s.n.). Mientras tanto La película opinaba que

hasta ahora ese género de películas solo había sido realizado con marcada fortuna por los norteamericanos, y el hecho de que también aquí se hayan efectuado admirablemente da idea de los progresos técnicos adquiridos por la cinematografía argentina, y particularmente por la casa Martínez y Gunche, que en ese sentido, es uno de sus mejores exponentes. (La Película, n. 186, 15 abr. 1920, p. 1)

Si en la última década del siglo 19, el principal problema habían sido las enfermedades infectocontagiosas y las condiciones de vida de los sectores populares, en las primeras décadas del siglo 20 se sumó el progresivo flagelo de las enfermedades de transmisión sexual. Potenciadas por el acelerado crecimiento de la población masculina y el consecuente aumento de la prostitución, la propagación de las venéreas impulsó, desde el higienismo, toda una serie de propuestas sociales de carácter preventivo. En 1921 se creó la Liga Argentina de Profilaxis Social, con un cuerpo consultivo integrado por profesionales y políticos ${ }^{15}$ y pensada casi exclusivamente para la lucha antivenérea. Con un accionar íntimamente relacionado con algunas iniciativas de orden eugénico, la liga inició una importante campaña de propaganda buscando su inspiración en Europa, donde la Primera

${ }^{15}$ Entre los nombres más relevantes puede mencionarse a su fundador Alfredo Fernández Verano y otras importantes personalidades de la época como Estanislao Zeballos, Joaquín V. González, Alfredo Palacios, Eleodoro Lobos, José Ingenieros y el ya mencionado José Luis Cantilo - por entonces intendente de Buenos Aires -, entre otros. 
Guerra Mundial había provocado una propagación de enfermedades sexuales similar. Con el objetivo de difundir lo mejor posible su mensaje precautorio, la liga apeló a todo tipo de estrategias, desde volantes, carteles y afiches hasta notas en los diarios y películas ${ }^{16}$.

La actividad de difusión se dirigió especialmente a los principales grupos de riesgo, con especial atención en los hombres jóvenes, sobre todo aquellos enlistados en el Ejército y la Marina. En este sentido, una de las más tempranas películas profilácticas de la que dan cuenta las publicaciones de la época es La sifilis y sus consecuencias, rodada en 1921 por Mario Gallo, pionero del cine argentino y autor de La revolución de mayo (1909), primera película de ficción nacional. Como otros profesionales del cine comercial, Gallo produjo ocasionalmente films de carácter educativo y científico como éste, que de acuerdo a la revista La Película ${ }^{17}$, había sido confeccionado por encargo del Ministerio de Guerra para ser exhibido ante los conscriptos en todos los cuarteles del país.

Aunque la película hoy se encuentra perdida, las publicaciones de la época sostienen que se trataba de un "un film de carácter científico en el cual se reflejan los horrores de la sífilis con todos sus derivados genéricos" (La Película, n. 273, 15 dic. 1921, p. 13). Este tipo de cintas, que muchas veces tocaban temas tabú para la época, como el sexo o la prostitución, contenían con frecuencia advertencias para los potenciales espectadores o directamente se declaraban no aptos para menores o señoritas. Paradójicamente, sus escandalosas temáticas, poco frecuentes en las pantallas comerciales, en ocasiones despertaron un exagerado interés en el público de la época, convirtiéndolos en insólitos éxitos de taquilla. Las compañías productoras del período, que como vimos fueron muchas veces responsables de la realización de estos films, vislumbraron pronto el potencial de este tipo de cintas y los presumibles beneficios de su explotación y no tardaron en amoldarlas a las exigencias del mercado, adoptando algunas de las mismas estrategias estéticas y narrativas del cine comercial.

En ese sentido, uno de los títulos más resonantes de la época fue La higiene en el matrimonio (1928), dirigida por Luis Moglia Barth, hoy más conocido por ser el autor de ¡Tango! (1933), primer largometraje argentino con sonido óptico. De acuerdo a las revistas de la época, en su primera semana de estreno el film había contado con "veinticuatro exhibiciones en el teatro Porteño y ciento dos en el teatro Nuevo"18 (Revista del Exhibidor, n. 52, 29 feb. 1928, s.n.), muchas de ellas a sala llena, marcando luego "verdaderos records de permanencia y de entradas en taquilla" (Ibid, s.n.) en todos aquellos lugares donde se exhibió, que incluyeron varias importantes ciudades del interior del país como Córdoba, Rosario, Mendoza, Mar del Plata y Bahía Blanca ${ }^{19}$. En los avisos publicitarios se aseguraba

\footnotetext{
${ }^{16}$ Para más información sobre la Liga Argentina de Profilaxis Social véase Sánchez (2007).

${ }^{17}$ Véase La Película, n. 273, 15 dic. 1921, p. 13.

18 Unos meses después, en el n. 602, del 5 de abril de 1928, la revista La Película, proporcionaba cifras actualizadas que seguían dando cuenta del éxito del film. En una época donde las películas permanecían apenas unos pocos días en cartel, la publicación consignaba que la cinta se había proyectado en veinte cines de la Capital y veinte cines de Rosario, con dos meses consecutivos de llenos en el Teatro Nuevo de Buenos Aires, una semana de llenos en el Teatro Porteño de la misma ciudad, además de seis llenos en el cine San Martín, dos en el Cine Rosario, dos en el Cine Capitol, cuatro en el cine La Bolsa, dos en el Cine Sol de Mayo y ocho en el Cine Casino, todos de la ciudad de Rosario.

${ }^{19}$ Véase La Película, n. 617, 19 jul. 1928, p. 24
} Hist. Educ. [Online] 
que se trataba del "film cultural que ha obtenido más rotundo éxito" (La Película, n. 602, 5 abr. 1928, s.n.), el "que en el momento da mayores entradas" (Revista del Exhibidor, n. 52, 29 feb. 1928, s.n.) y se alentaba a los empresarios a verlo como un verdadero "elemento animador de taquillas" (Ibid., s.n.).

Se trataba de un documental armado en base a una serie de cortos científicos germanos al que se le habían agregado varias secuencias de carácter ficcional filmadas en Buenos Aires, en los estudios de la Unión Cinematográfica Argentina. Hoy también perdido, es posible reconstruir someramente su contenido a través de las reseñas de época. Así, La Película afirmaba que La higiene en el matrimonio era una magnífica obra científico-cultural,

urdida en una simple trama, a la que sirve de base la aún más simple historia de dos matrimonios. [...] Ofrece la visión de cómo se desenvuelve plácida, normal y encantadoramente la existencia del matrimonio joven que se ama sí, pero que no por ello deja de observar las elementales reglas de higiene, tan íntimamente ligadas a la relación sexual: a la par; muestra también la forma en que el otro matrimonio, joven y amante como el anterior, cumple con sus deberes conyugales, pero olvidando por completo de una serie de reglas vinculadas estrechamente con la acción fisiológica del amor. Entretejiendo el desarrollo de la trama, van demostrándose al espectador, en forma eminentemente, científica y emocional, la función que desempeñan los principales órganos, así cuando se cuida de las reglas como cuando de ellas se abandona por completo. Finalmente el doloroso desenlace del matrimonio que olvidó, por marchar por equivocada senda, los principios de moral que en el amor existen, da la pauta de lo que puede traer aparejado el querer torcer los sabios designios de la madre naturaleza, mientras que al otro matrimonio, que contempló y practicó las reglas del buen amor, ve florecer en la prolongación de su idilio, el poema de la vida, hecho carne en un bello y robusto bebé, expresión suprema del cariño de dos seres. En síntesis, es esta una bella película que, si bien no debe ser vista por menores, debe en cambio, servir de provechosa lección a toda persona, de ambos sexos, que aspire realmente a cumplir en el matrimonio con la bella y suprema luz que a este le está destinada. (La Película, n. 617, 19 jul. 1928, p. 24)

Estrenada casi en los albores del cine sonoro, ante un público para entonces sumamente sofisticado, era evidente que la espectacularidad de las atracciones, presente en las crudas cirugías de los primeros films científicos o en las sorprendentes imágenes fotomicrográficas de las tempranas películas higienistas, ya no era suficiente para satisfacer el cada vez más exigente gusto de estas nuevas audiencias. Los avisos publicitarios de hecho aseguraban que el film no contenía operaciones ${ }^{20}$ y prometían, en cambio, una mirada más artística que audaz a "las intimidades de la vida matrimonial para demostrar con altura y elevación moral los perjuicios y desgracias que ocasionan a la sociedad la ignorancia de ciertos matrimonios" (Revista del Exhibidor, n. 52, 29 feb. 1928, s.n.). En este contexto, la presencia de secuencias ficcionales en el film - que, como mencionamos, fueron especialmente rodadas en Buenos Aires para ser anexadas al documental científico alemán que se tomó de base -, sumadas a la temática sexual funcionaron como una perfecta

${ }^{20}$ Véase a Película, n. 602, 5 abr. 1928, s.n. Hist. Educ. [Online] $\quad$ Porto Alegre v. 19 n. 46 Set./dez., 2015 p. $51-73$ 
estrategia comercial para garantizar el interés de este nuevo espectador cosmopolita. Sin embargo, los desnudos, que estos films seguramente incluían - o al menos sugerían, figura 4 , pueden ser considerados como uno de los últimos vestigios del cine de atracciones que aún generaba fascinación en el público.

Figura 4 -

Aviso publicitario de La higiene en el matrimonio.

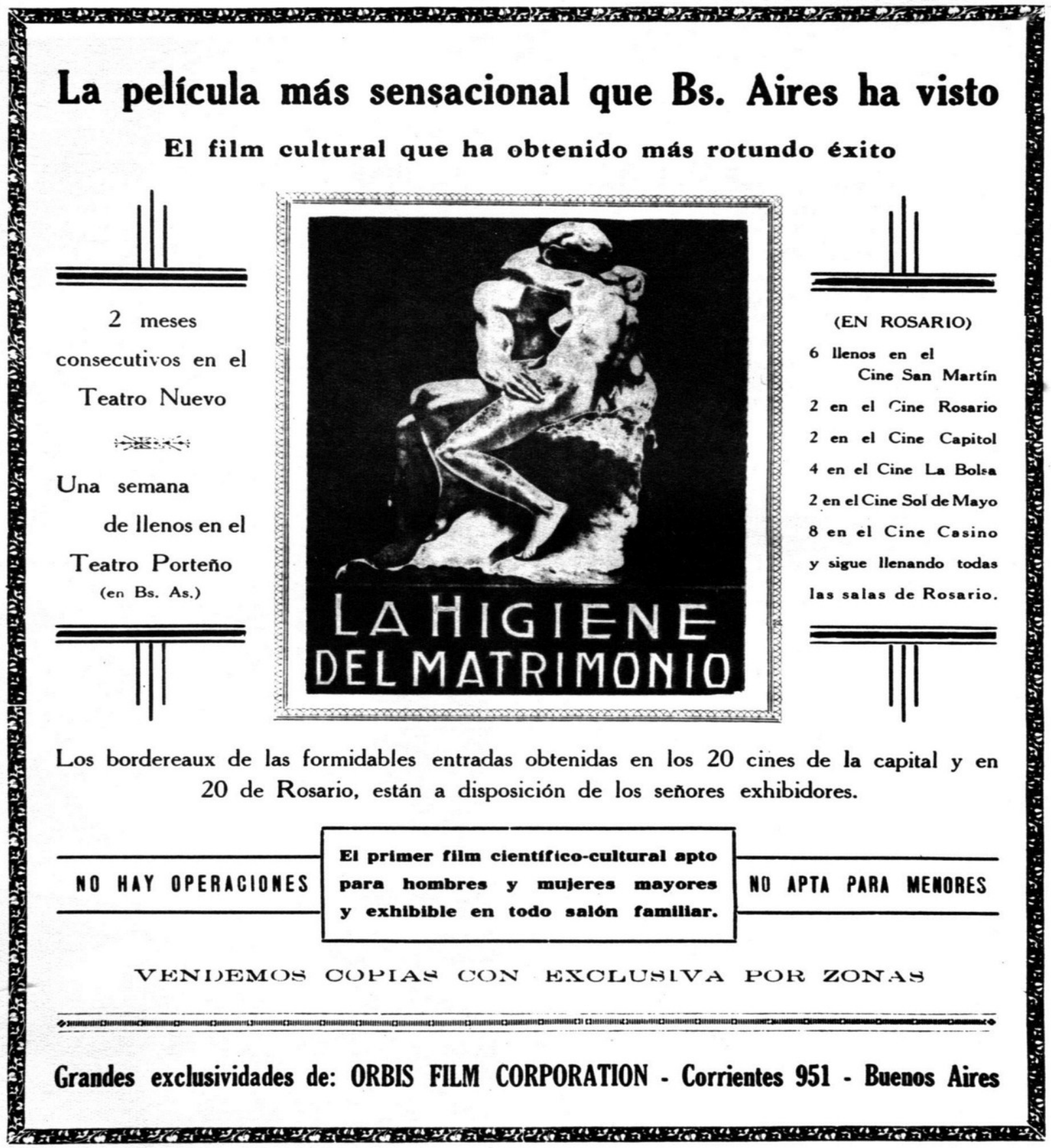

Fonte: Luis Moglia Barth, 1928, publicado en La Película, n. 602, 5 abr. 1928. 
Estos temas y formas de relato siguieron explotándose en los años subsiguientes y con el tiempo terminaron por desplazar a los elementos más científico-didácticos, que prevalecieron casi como una excusa para poder ahondar en temáticas tabú, evadiendo la censura. Nació así un lucrativo género que las publicaciones del momento bautizaron como películas realistas que, tomando a la ciencia como coartada, incursionaron en tramas de abierto contenido sexual. El principal exponente de este género en el país fue el director Julio Irigoyen, llamado el rey de las quickies - películas rodadas rápidamente, sin esmero y con un exclusivo espíritu de negocio. Con títulos como La casa del placer (1929), Amor prohibido (1929), Los templos del vicio (1931), Noches de lujuria (1932) o Traficantes de carne humana (1932), Irigoyen se declaraba un verdadero luchador en pos de la educación sexual de los jóvenes. Así en un aviso publicitario de su productora Buenos Aires Film, el director aseguraba a los empresarios que exhibiendo sus películas obtendrían grandes réditos económicos a la vez que tranquilidad de conciencia:

¡Se acabó la crisis! Empresario amigo: exhiba en su sala nuestras películas realistas, todas ellas de temas valientes que, a pesar de su crudeza, no llegan jamás a las burdas escenas pornográficas. Nuestros propósitos son más elevados y el material que le ofrecemos, de carácter realista, son films seleccionados que llevan un fin noble, que debiera ser el principio de una gran cruzada en bien de la educación sexual... Dedique un día por semana en su sala a estos espectáculos exclusivamente para mayores que a más de ser una solución para los días flojos, hará una buena obra en bien de la humanidad y le brindará a su público un espectáculo moderno, como se exhibe en las principales salas del mundo. (Citado en Maranghello, 2001, p. 71)

Ninguna de las películas de Irigoyen han sobrevivido hasta nuestros días y existe muy poca información sobre las características y contenidos de las mismas. Sin embargo, un breve anuncio publicitario de Los placeres sexuales y sus consecuencias (1929), uno de los títulos más sugerentes de su nutrida filmografía, proporciona una sucinta idea de los temas abordados en este tipo de producciones pseudo-científicas:

Película realista no apta para menores [...] que comprende una finalidad altamente científica, pues en su desarrollo se demuestra cómo y dónde se contraen las enfermedades sociales, cómo se curan y cómo se previenen. Escenas de cabaret y de todo otro sitio pecaminoso con pasajes voluptuosos sirven de encabezamiento a la película continuándola con tratamientos médicos curativos y preventivos, intervenciones quirúrgicas, presentación de tarados, heredos (sic), etc. (La Película, n. 700, 20 feb. 1930, p. 14)

Si en un principio las temáticas escandalosas y las mujeres ligeras de ropa sirvieron a los empresarios para competir con el cada vez más arrollador avance del cine sonoro, para mediados de la década del 1930, el interés por este tipo de films parece haberse extinguido por completo. Sin embargo, a partir de este breve recorrido por los hitos del cine científico en la Argentina, es posible afirmar que durante las tres largas décadas del período silente, estas películas no sólo sirvieron a los propósitos didácticos, profilácticos o higienistas para las cuales fueron - o al menos declararon ser - muchas veces concebidas, sino que además 
formaron plena parte del divertimento popular de la época, trascendiendo las fronteras de los establecimientos sanitarios y educativos e integrándose armoniosamente a los catálogos y programas del cine comercial con el que, en ocasiones, incluso compitieron. Asimismo, los cineastas a cargo de estas producciones, en tanto partícipes activos de la incipiente industria fílmica local - percibieron tempranamente el latente negocio detrás de estos films y, sirviéndose de muchas de las estrategias del cine comercial, los explotaron y adaptaron al cambiante gusto del público de la época. Un artículo titulado Las películas científicas deben incluirse en los programas, publicado en la revista Excelsior en marzo de 1920, resume a la perfección algunas de estas ideas:

Un craso error es creer que el público rechaza las películas instructivas. Lo que hay en el fondo es que el empresario no acepta esa clase de asuntos por un prejuicio antiguo. En efecto, hace años se abusaba en la inclusión de películas de esta naturaleza en la secciones, motivando protestas que se tradujeron en manifestaciones adversas. En realidad las cintas instructivas gustan y usadas con moderación producen resultados altamente didácticos. (Excelsior, n. 314, 17 mar. 1920, p. 1671)

\section{Un cine huérfano}

Si bien gran parte del cine científico realizado en la Argentina durante el periodo silente se encuentra perdido, existe un considerable número de films de este género que duermen sin catalogar en archivos locales o que, desperdigados por establecimientos educativos, hospitales y otras dependencias institucionales, aguardan el momento de ser redescubiertos ${ }^{21}$.

En los inicios de la década de 1990, la comunidad de archivistas fílmicos bautizó a este tipo películas como orphan films o film huérfanos, englobando con esta metáfora no sólo a aquellas cintas sin copyright o potencial comercial evidente, sino también a todo tipo de material fílmico deteriorado, no estrenado, censurado u olvidado. En este trabajo - que se inscribe en el resurgido interés por esta clase de materiales, cuyo valor cultural e histórico ha sido desdeñado por años - nos hemos propuesto rescatar algunos de estos films de su actual estado de invisibilidad. Mediante el análisis de algunos de los pocos exponentes de éste género que hoy pueden consultarse y de un cuidadoso rastreo hemerográfico, hemos intentado reconstruir tanto las características como las circunstancias de producción, distribución y exhibición de gran parte de ese material olvidado. La premisa con la que iniciamos este ensayo sostenía que, al igual que el cine se había convertido en una herramienta esencial de la cultura científica de la época, la ciencia había funcionado como un elemento integral del cine comercial y en un nivel más amplio del divertimento popular de las primeras décadas del siglo 20.

21 De hecho, tanto Operaciones del dr. Posadas (Eugenio Py, ca. 1899) como Instituto Modelo de Clínica Médica (Eduardo Martínez de la Pera y Ernesto Gunche, 1922) fueron encontrados en instituciones relacionadas con la salud. 
Así, de un primer período en el que se explotó el componente espectacular de los tempranos films científicos se pasó, hacia mediados de la década de 1920, a una etapa en la que, las atracciones ocuparon un segundo plano y se adoptaron estrategias narrativas que, por momentos, acercaron a estas películas al cine de ficción. Así, lejos de ser dos términos incompatibles, educación y espectáculo convivieron y se amalgamaron en estos films desde los orígenes mismos del medio. El estudio de estos "materiales huérfanos", nos permite concluir, entonces, que la importancia de este temprano cine científico excede el hasta ahora restringido ámbito de la ciencia al que hace años fue confinado y es necesario comenzar a verlo también como una parte relevante y casi desconocida de la historia del cine y la cultura popular de los inicios del siglo 20.

\section{Bibliografía}

BAPTISTA, Tiago. II faut voir le maître: a recent restorationof surgical films by E.-L. Doyen (1859-1916), Journal of Film Preservation, Bruselas: Fiaf, n. 70, 2005, p. 42-50. Disponible en: <http://www.fiafnet.org/pdf/uk/fiaf70.pdf> . Acceso: 20 enero, 2014.

DE AJURIA, Julián. El cinematógrafo: espejo del mundo. Buenos Aires: Guillermo Kraft, 1946.

GAUDREAULT, André. Cinema delle origini o della cinematografia-attrazione. Milán: II Castoro, 2004.

GUNNING, Tom. Atracctions, trucages et photogénie: l'explosion du present dans les films á truc français produits entre 1896 et 1907. En: GILI, Jean A.; MARIE, Michel; PINEL, Vincent (eds.). Les vingt premières annés de cinéma français. Paris: Sorbonne Nouvelle/AFRHC, 1995, p. 177-193.

GUNNING, Tom. An aesthetic of astonishment: early film and the (in)credulous spectator. En: WILLIAMS, Linda. Viewing positions: ways of seeing films. New Brunswick: Rutgers University Press, 1994, p. 114-133.

KESSLER, Frank. La cinématographie comme dispositif (du) spectaculaire. Cinémas: revue d'études cinématographiques, v. 14, n. 1, 2003, p. 21-34. Disponible en: $<$ http://id.erudit.org/iderudit/008956ar > . Acceso: 9 mayo 2011.

LANGSTON, Lacey Joy. The fear within: early scientific film and its influence on the horror genre. San Diego: San Diego State University, 2010. 41f. Tesis (master of arts). San Diego State University. Disponible en: <http://hdl.handle.net/10211.10/316>. Acceso: 5 marzo 2014.

LEFEBVRE, Thierry. La collection des films du dr. Doyen. 1895, Paris: AFRHC, n. 17, 1994, p. $100-114$.

LEFEBVRE, Thierry. Le docteur Doyen, un précurseur. En: MARTINET, Alexis (ed.). Le cinéma et la science. Paris: CNRS, 1995, p. 70-77.

LOSADA, Matt. La mosca y sus peligros: science, affect and the microscopic sublime. Revista de Estudios Hispánicos. St Louis: Washington University in St. Louis, v. 46, n. 3, 2012, p. 465-480.

MARANGHELLO, César. Julio Irigoyen, el torbellino de Buenos Aires. La mirada cautiva, Buenos Aires: Museo del Cine Pablo Ducrós Hicken, n. 5, 2001, p. 59-86. 
OSTHERR, Kirsten. Contagion and the boundaries of the visible: the cinema of world health. Camera Obscura, Santa Barbara: Department of Film and Media Studies, University of California, v. 17, n. 2, 2002, p. 1-39.

PALMA, Héctor. Gobernar es seleccionar: apuntes sobre la eugenesia. Buenos Aires: Baudino, 2002.

PEÑA, Fernando M. Cien años de cine argentino. Buenos Aires: Biblos, 2012.

QUIROGA, Horacio. El cine nacional. El Hogar, Buenos Aires, n. 973, 8 de junio de 1928, s.n. QUIROGA, Horacio. El cine educativo. Patagonia, Atlántida, n. 226, 3 de agosto de 1922, s.n. QUIROGA, Horacio. El cine en la escuela: sus apologistas. Caras y Caretas, n. 1116, 21 de febrero de 1920, s.n.

REVISTA DEL EXHIBIDOR. (1926-1933).

REVISTA EXCELSIOR. (1918-1920).

REVISTA FOTOGRÁFICA ILUSTRADA DEL RÍO DE LA PLATA. (1902-1906).

REVISTA IMPARCIAL FILM. (1918-1933).

REVISTA LA PELÍCULA. (1919-1933).

SÁNCHEZ, Norma Isabel. La higiene y los higienistas en la Argentina (1880-1943). Buenos Aires: Sociedad Científica Argentina, 2007.

SERRA, María Silvia. Cine, escuela y discurso pedagógico: articulaciones, inclusiones y objeciones en el siglo 20 en Argentina. Buenos Aires: Teseo, 2011.

TOSSI, Virgilio. Cinema before cinema: the origins of scientific cinematography. London: British Universities Film \& Video Council, 2005.

TÚMBURUS, Juan. Síntesis histórica de la medicina argentina. Buenos Aires: El Ateneo, 1926.

ANDREA CUARTEROLO es doctora en Historia y Teoría de las Artes por la Universidad de Buenos Aires. Es investigadora del Consejo Nacional de Investigaciones Científicas y Técnicas y del Instituto Historia del Arte Argentino y Latinoamericano y dirige el proyecto de investigación Imagen reproducible y educación: la fotografía y el cine como auxiliares pedagógicos en la argentina de fines del siglo 19 y principios del 20, subsidiado por la Agencia Nacional de Promoción Científica y Tecnológica.

Endereço: Acoyte $5024^{\circ} \mathrm{A}$ (1405) - CABA - Argentina.

E-mail: acuarterolo@yahoo.com.

Recebido em 8 de março de 2015.

Aceito em 17 de julho de 2015. 